\title{
PUBLICAÇÃO ACADÊMICA: capital simbólico na economia cultural da pesquisa
}

\section{Uma entrevista com John B. Thompson}

\section{Lucídio Bianchetti*}

\section{Elisa Maria Quartiero ${ }^{* *}$}

Estivemos na Universidade de Cambridge, Inglaterra, no ano letivo de 2009/2010, para entrevistar o Dr. John B. Thompson, professor de Sociologia na Jesus College desta Universidade. Nascido em Minneapolis (Estados Unidos), o professor John B. Thompson está radicado na Inglaterra desde 1970. Suas principais áreas de pesquisa, dentro da abordagem da Teoria Social Crítica, envolvem a teoria social e política contemporânea, sociologia da cultura moderna, organização social das indústrias de mídia, impacto social e político das tecnologias da informação e da comunicação e formas cambiantes de comunicação política. Em 2001 ganhou o prêmio Amalfi, um dos mais importantes na área de Ciências Sociais, na Europa, com um trabalho sobre escândalo político. O professor Thompson tem trabalhado desde 2000 com as mudanças na estrutura da indústria de publicação de livros na Grã-Bretanha e nos Estados Unidos. A primeira fase da pesquisa foi focada na publicação acadêmica e os resultados estão na obra Livros na Era Digital (2005) ${ }^{1}$. A segunda fase da pesquisa teve como preocupação as mudanças nas publicações comerciais, de interesse geral e a fabricação de best-sellers, cujos resultados foram publicados no livro Comerciantes da Cultura (2010) ${ }^{2}$. No Brasil, tem três livros publicados: Ideologia e cultura moderna: teoria social crítica na era dos meios de comunicação de massa (1995), A mídia e a modernidade: uma teoria social da mídia (1998) e O escândalo político: poder e visibilidade na era da mídia (2002), todos pela editora Vozes.

\footnotetext{
* Doutor em Educação: História, Política e Sociedade pela Pontifícia Universidade de São Paulo. Professor da Universidade Federal de Santa Catarina. E-mail: lucidiob@uol.com.br

** Doutora em Mídia e Conhecimento pela Universidade Federal de Santa Catarina. Professora da Universidade do Estado de Santa Catarina. E-mail: elisa.quartiero@udesc.br

${ }^{1}$ Cf. THOMPSON, John B. Boods in the digital age. Cambridge, UK e Malden, USA: Polity Press, 2005.

${ }^{2}$ Cf. THOMPSON, J. B. Merchants of Culture. The plublishing Business in the Twenty First-Century. UK: Polity Press, Cambridge, 2010.
} 
Revista Linhas: Estamos na Universidade de Cambridge, no escritório do professor John B. Thompson e começamos perguntando-lhe a respeito do seu processo de formação pósgraduada: em que condições foi realizado e em que período.

John B. Thompson: Eu fiz o primeiro ciclo, o meu bacharelado, na Universidade de Keele, em Staffordshire, e estudei Sociologia e Filosofia. Graduei-me lá em 1975 e concorri em Cambridge para realizar o doutorado e fui aceito. Então, vim em setembro de 1975 e passei a ser orientado pelo professor Anthony Giddens, que era na altura um conhecido sociólogo. A dinâmica de funcionamento do doutorado naquela época não é muito diferente de agora: temse um orientador e todos os inputs relacionados com o trabalho de doutorado vêm do orientador, não tínhamos nenhuma coordenação de doutorado ou qualquer coisa desse gênero. Basicamente tem-se um orientador e ele guia-nos. Então, eu vim, revi bastante os meus planos originais nos primeiros três meses do meu tempo em Cambridge. Penso que é completamente normal, e finalmente elaborei um plano para o meu doutorado, realizei-o e terminei-o, mais ou menos, em três anos, por volta de 1978. Eu terminei a tese e tive a sorte de conseguir o que em Cambridge chamávamos de bolsa (research fellowship) naquele tempo, que é uma posição privilegiada. Submeti a tese à avaliação em 1979. Essa foi minha experiência como estudante de doutorado: essencialmente fazer a minha pesquisa e receber feedback do orientador e acabei em cerca de três, três anos e meio, o que é, como sabem, pouco usual. Normalmente, em Cambridge, os estudantes de doutorado demoram quatro anos, por vezes cinco. Isto é bastante comum, embora tentemos que eles acabem antes deste prazo. Eu levei três anos e meio, mas tentamos que eles acabem em quatro anos. Esse é o objetivo.

Revista Linhas: Thompson, como analisa a sua relação com o seu orientador durante esse período?

John B. Thompson: Teria que falar sobre a especificidade do doutorado em Cambridge. Quero dizer, a forma como funciona e as nossas disciplinas: os estudantes de doutoramento são inteiramente autônomos. Tens de saber o que queres fazer, tens que elaborar um plano de investigação, uma proposta, trabalhar nela, conceitualizar o teu tema, fazer a investigação e escrever a tese. O teu orientador está lá como alguém que fornece feedback sobre as tuas ideias e planos e tem o papel de te supervisionar. O meu orientador fez isso: foi um bom orientador e o que é mais importante, era muito experiente e tivemos uma boa relação. $\mathrm{O}$ processo foi muito frutífero e produtivo para mim. Quando lhe dava material para ler, lia e 
devolvia-me com comentários úteis. Estava lá para estruturar o projeto e a pesquisa e ajudarme a definir o que era exequível, as questões corretas e dava-me feedback do que eu escrevia. Ele era excelente, muito bom. Tive muita sorte em ter um orientador tão bom e experiente que tinha muito conhecimento sobre o assunto que pesquisava e que era também uma pessoa muito simpática; permanece um amigo muito próximo e 30 anos depois é um dos meus amigos mais chegados. Nem sempre funciona assim, como sabe, mas eu tive sorte.

Revista Linhas: Como foi a passagem da condição de orientando à de orientador? Passada a defesa começou imediatamente a orientar?

John B. Thompson: Não comecei de imediato porque tive a sorte de conseguir uma bolsa de investigação (research fellowship) no Jesus College, onde permaneci por cinco anos como bolsista, o que significou que não tinha de dar aulas nem orientar ninguém. Eu orientava os alunos do bacharelado porque gostava, mas não era obrigatório para mim. Dei algumas aulas, mas por opção minha. Assim, tive cinco anos para continuar a minha investigação e para publicar a minha tese em livro e depois para começar um novo projeto e publicar outro livro e por aí em diante. Tive este período de graça por cinco anos, o que foi uma sorte e não tive nenhum estudante de doutorado na altura. Depois, no fim desse tempo, em 1985, surgiu uma vaga na Universidade e eu consegui o emprego. A partir daí tornei-me professor na Universidade e assim que comecei a dar aulas, passei a ter estudantes de doutorado. Se me recordo bem, o meu primeiro estudante de doutorado foi em 1986. Comecei a receber estudantes de doutorado em 1986/87 e entre o final dos anos 1980 e início dos anos 1990, tive uma série de estudantes de doutorado. Penso que foi essa a cronologia.

Revista Linhas: Fazendo uma comparação entre o período em que você realizou o doutorado e o atual, diria que os doutorandos que ingressam hoje em Cambridge têm condições de realizar pesquisas de maneira autônoma ou precisam dos orientadores mais do que naquele tempo?

John B. Thompson: Penso que não existe uma resposta simples para essa questão porque, parece-me, isso depende sobremaneira do estudante. É o que aprendi acima de tudo nos 20 anos de orientação de estudantes de doutorado. O que aprendi de mais importante é que temos de escolher cuidadosamente os nossos estudantes, porque é muito, muito difícil fazer um 
doutorado aqui. É um nível muito elevado, esperamos uma performance de alto nível e é esperado que os doutorandos sejam muito autônomos. Não dou atenção excessiva aos meus estudantes; eu espero que eles sejam autônomos. Quero orientá-los, mas não quero tomar conta deles como se fossem crianças. Não. Eu quero que sejam pesquisadores e por isso doulhes imensa independência e autonomia. E nem todos conseguem aguentar. Por isso, em 20, 25 anos de orientação tive muitos estudantes magníficos e também tive alguns que não conseguiram concluir. Ou não aguentaram, ou, como em um caso, para ser honesto, ela não era suficientemente boa e foi um erro ter assumido sua orientação. Consigo ver isso em perspectiva: alguém me abordou e de certa forma levou-me a isso e eu pensei: “ok, eu vou dou-lhe uma oportunidade”. Mas no fim não foi uma boa decisão. E assim, há vários anos que sou muito cauteloso com os estudantes que decido orientar. Quero ter a certeza de que são absolutamente top, que são muito capazes, muito, muito inteligentes e que aguentam os desafios de realizar pesquisa independente por três a quatro anos! Que têm o compromisso e a dedicação para o fazer. Assim, eu diria que por ser muito seletivo, os estudantes que tenho agora são tão autônomos quanto os estudantes que tinha há 20 ou 25 anos. Mas isso é porque eu não escolho estudantes que considere serem fracos e que por isso irão precisar de muito apoio.

Revista Linhas: Professor Thompson, poderia explicitar mais sobre a organização da pósgraduação em Cambridge que parece se diferenciar da proposta implementada a partir do Pacto de Bolonha, para as universidades europeias: três anos de graduação, dois de mestrado e três de doutorado.

John B. Thompson: Sabe, Cambridge é um pouco exterior a tudo isso. Não temos o sistema de dois mais três, na pós-graduação: temos essencialmente um sistema de um mais três ou, especificamente, de nove meses mais três anos. Não temos um mestrado padrão em programa nenhum da Universidade. Temos programas que chamamos "in-fills" e outros programas desse tipo em diversas faculdades e departamentos diferentes. Pretende ser um ano de pósgraduação ou mesmo nove meses de pós-graduação com uma forte componente de envolvimento em pesquisa. É entre os estudantes do curso de nove meses que iremos selecionar alguns para continuar os estudos de doutorado. O “in-fill” é um mecanismo de triagem para selecionar os estudantes que pensamos ser bons o suficiente para continuar no doutorado. Assim, qualquer aluno que me escreva - e muitos vão escrever -me e dizer: "eu gostaria de ir para Cambridge para fazer o doutorado (e assim por diante) consigo" - e se não 
tiver certeza sobre a sua capacidade e se eles realmente podem concluir o doutorado, simplesmente incentivo-os a fazer o "in-fill” e então temos nove meses para ver como se saem, se são bons o suficiente e assim por diante. E o "in-fill” é muito exigente, muito difícil: temos um nível de corte entre 60, 67 pontos. Então se um estudante tem uma média que está abaixo disso, não é permitido que, tecnicamente falando, continue no doutorado. É muito difícil conseguir esta pontuação, sendo, portanto, um mecanismo bastante eficaz de filtragem. Mas tudo isso significa que não temos realmente o sistema de Bolonha: temos um ano e mais três. Cambridge, como eu disse antes, não é provavelmente um exemplo muito típico. Nós somos assim: é uma instituição tão idiossincrática de tantas formas, e que não gosta de tentar adaptar-se aos modelos que vêm de fora. Então eu acho que você será aconselhado a não considerar Cambridge como um exemplo sintomático ou indicativo das universidades britânicas. Eu acho que provavelmente vai descobrir que muitas outras universidades britânicas têm cursos de mestrado de dois anos e eu nem sequer sabia.

Há muitas diferenças entre o modo como funciona a pós-graduação em Cambridge e o modo como funciona, por exemplo, na América do Norte. A principal diferença é que não temos uma componente de ensino para o doutorado. Se quiser uma componente de ensino, tem que fazê-lo no grau “in-fill”. Nós não temos nenhum elemento de ensino para além deste. Mas nos Estados Unidos, como sabe, qualquer estudante que queira ser um estudante de doutorado tem de fazer dois anos de trabalho de curso antes de ser autorizado a fazer a sua tese de doutorado. Aqui vai-se direto para a tese de doutorado: desde o início do primeiro ano o doutorando está trabalhando sua tese. E essa é uma diferença muito grande.

Revista Linhas: Gostaríamos agora de falar sobre a situação dos professores universitários e dos pesquisadores ingleses dentro das políticas atuais para a pós-graduação que têm a ênfase na publicação e em uma avaliação que quantifica e certifica esta produção. Como você analisa este momento da vida acadêmica dos pesquisadores?

John B. Thompson: Bem, para entender esta dinâmica na Grã-Bretanha é necessário ter em conta o quadro do que chamamos o "exercício de avaliação de pesquisa” (RAE), que agora está sendo renomeado como “quadro de excelência de pesquisa”, mas que é apenas outra modalidade da mesma coisa. Estas medidas impactam todo o meio acadêmico na GrãBretanha - o setor universitário ou do ensino superior e todas as instituições de ensino superior - por um lado, em termos das relações entre o exercício de avaliação da pesquisa (ERA), e do financiamento institucional, por outro. 
Este é o fato fundamental sobre a educação superior no Reino Unido que molda todos estes assuntos. Herdamos esse exercício de avaliação de pesquisa do governo de Thatcher, década de 1980, que o introduziu e permaneceu em vigor desde então, embora tenha sido por meio de diferentes formas e tenha se modificado ao longo do tempo, mas na essência continua o mesmo. Isto é: a cada cinco ou seis anos ou em algum momento cada departamento é submetido a este processo de avaliação de suas pesquisas, uma avaliação muito exigente em que a produção dos membros dos grupos das pesquisas em andamento do departamento ou da faculdade é avaliada. Na última vez que isto ocorreu cada pesquisador precisava apresentar quatro publicações. Quero dizer, pode ter publicado muito mais do que isso - e muitas pessoas o fizeram - mas o processo de avaliação foca em quatro publicações. Cada pesquisador tem de escolher quatro das suas publicações para enviar para este processo de avaliação.

Portanto, isso é algo realmente crucial no sistema de ensino superior no Reino Unido, e há uma enorme quantidade de pressão sobre todos os acadêmicos e todos os departamentos e chefes de departamento, e assim por diante, para garantir que todos os membros da instituição produzam resultados com um volume e qualidade suficientes para constituir uma apresentação forte para a RAE.

Esta avaliação cria uma enorme quantidade de pressão para publicar, mas não apenas a publicação pela publicação. Não é o objetivo do exercício avaliar apenas o volume de produção: é um exercício de avaliação da qualidade da produção.

Mas tem que haver certo volume para isso. Há que ter, pelo menos, quatro produtos. Mas é um processo imensamente complicado, pois levanta muitas questões difíceis. Só para lhes dar um exemplo: no campo das ciências sociais e humanas uma saída muito tradicional e que é frequentemente considerada como uma espécie de padrão dourado da produção acadêmica é a monografia de pesquisa - o livro. Uma produção em que o pesquisador pode ter passado cinco anos trabalhando e que conta apenas como uma produção. As pessoas, fora do mundo acadêmico, realmente não entendem este tipo de problema e podem dizer: “certamente os estudiosos podem produzir quatro trabalhos em quatro anos, certamente que não é pedir muito!”. Mas o modelo é aquele das ciências exatas em que a produção está ligada a artigos ou algo assim. E realmente não entendem que em uma área - onde a produção é diferente - o resultado do trabalho pode ser um livro de 400 páginas! Esta produção está sendo posta na mesma escala que um artigo de dez páginas: um livro de 400 páginas conta exatamente quanto um artigo de dez páginas. É aí que esse sistema de calibração começa a parecer pouco refinado. Portanto, esta é uma área altamente controversa e difícil e há muitas discussões nos dois sentidos sobre os prós e contras deste sistema. Mas temos que viver com essa avaliação e 
ela molda a vida produtiva e a vida acadêmica de todos nós agora e não há como escapar. Este exercício de avaliação moldou a natureza da produção de conhecimento acadêmico de uma forma que extrapola sua intenção. Foi destinado a ser uma medida, em algum sentido, do que os acadêmicos faziam, mas, como tantas destas medidas, a escala começa a moldar a atividade da produção em si. Ou seja, interfere na maneira como as pessoas produzem, porque têm que adaptar as suas atividades produtivas para ajustar-se à escala. Assim, a consequência disto é que há uma grande pressão sobre as pessoas para pararem de escrever as monografias acadêmicas porque se você tem uma monografia acadêmica - em que passou cinco anos trabalhando nela - que tem dez capítulos, do ponto de vista da RAE, é melhor que tivesse publicado apenas dez artigos. Você está muito melhor no ranking se fizer isso, ou mesmo apenas quatro artigos. Daí pergunta-se: por que publicar um livro que tem dez artigos nele? Você não recebe nenhum crédito por isso. Somente o nível equivalente a um artigo. Então, começa a moldar a forma como as pessoas pensam sobre o conhecimento e qual o tipo, a forma em que o seu conhecimento é produzido. E esse é o perigo deste tipo de sistema, porque deixa de ser simplesmente uma maneira de medir o que as pessoas fazem e começa a afetar o que eles fazem! E a forma como estão produzindo conhecimento. E as pessoas que estão administrando o sistema acham difícil pôr as suas mentes em torno disso e avaliar esta questão com outros parâmetros. Eles têm sido muito rígidos na maneira de pensar sobre isso. Um caminho que é muito tacanho, na verdade.

Revista Linhas: E então, com essa diferença entre as áreas, talvez possamos dizer que para a área educacional e a de humanidades em geral há uma pressão para publicar em pouco tempo o que precisaria de mais tempo para ser pensado, organizado, refletido.

John B. Thompson: Sim! Isso sempre foi parte do problema. Bom, como eu disse, tratam um livro de 400, 500 páginas exatamente da mesma maneira e dão o mesmo valor que a um artigo de dez páginas. E isso não me parece fazer qualquer sentido. Vejamos um estudioso em História: Ele passa cinco anos escrevendo o grande trabalho "A História Econômica do Terceiro Reich”. O livro sai e todos dizem que é uma obra de grande erudição, que mudou a nossa maneira de pensar a história da Alemanha do século 20 e do período Nazi. E o autor levou cinco anos para escrevê-lo e talvez essa seja a única coisa que ele produziu. Esta pessoa está numa posição extremamente frágil no RAE, porque ele tem apenas uma submissão - um produto! - para apresentar. Portanto, isto é manifestamente absurdo, na minha opinião, e evidencia uma pobreza de pensamento em termos de como está a produção, a qualidade e o 
impacto da obra intelectual. É o método de burocratas da medição, que ao tentar medir tudo e contabilizar tudo provocam consequências perversas. Há algum sinal de que algumas das pessoas responsáveis pela criação destes processos estão começando a ouvir as mensagens e estão começando a perceber que deve haver uma diferença entre o que denominam trabalho e o que chamam de produções, pois um trabalho pode constituir duas ou três ou quatro produções.

E também, para voltar à sua pergunta, sim, é claro, há a pressão para publicar e se não fizer isso, se não produz e, especialmente, se não tem essas quatro produções, vai estar numa posição fraca e pode ser empurrado para fora da academia pela aposentadoria.

Isso acontece muito no Reino Unido agora: as pessoas estão sendo aposentadas mais cedo. É muito difícil fazer isso, pois têm que lhes pagar, mas podem fazer com que saiam e isso acontece muito porque algumas pessoas simplesmente não são suficientemente produtivas para a RAE e para que não fiquem mal vistos no departamento de submissões, são aposentados. Entre os jovens pesquisadores, eles sabem desde o primeiro dia de trabalho na Universidade que têm que ter produção para a RAE.

Eu acredito que há outras maneiras, maneiras mais inteligentes para pensar sobre essas coisas, mas os burocratas querem medidas simples e querem alguma coisa que seja comparável, portanto quatro produções. O que acontece como consequência, é que certos setores do mundo acadêmico efetivamente dominantes tornam-se as bases com as quais julgam-se todos os outros. É uma espécie de imperialismo disciplinar pela porta dos fundos.

Revista Linhas: Muitos desses burocratas que gerem este processo dizem que as novas tecnologias são uma ligação ou uma maneira de economizar tempo para produzir mais. Como você analisa as mudanças possibilitadas pelas tecnologias para a produção acadêmica, isto é, revistas, livros nesse novo contexto?

John B. Thompson: O impacto das novas tecnologias na esfera da produção varia fortemente de campo para campo e de forma de produção para forma de produção.Portanto hoje, o maior impacto foi inevitavelmente naqueles indivíduos para os quais a revista acadêmica é a principal forma de produção intelectual, pois a migração para o ambiente on-line em publicação de revistas acadêmicas aconteceu durante os anos de 1990, e em 2000 já estava muito bem desenvolvido. No início dos anos 2000 era lugar-comum entre os periódicos acadêmicos - quer no campo das ciências em geral, quer das ciências sociais e humanas em particular - apresentarem-se de forma on-line. A migração tem sido muito rápida e muito 
decisiva e na esfera da publicação do livro é uma história muito mais complicada, não acontecem no mesmo tipo de forma, tem sido muito irregular e muitas experiências foram realizadas a partir da década de 1990, mas só algumas continuam até os dias atuais.

Relativamente a como afeta o que os pesquisadores fazem, em termos de resultados produtivos, provavelmente não os afeta tanto. Basicamente, como fazemos para divulgar nossa produção? Enviamos um arquivo, que é o que temos estado fazendo há 10 ou 15 anos e ter esse arquivo on-line ou em um disco, não faz tanta diferença, não afeta muito a atividade produtiva. Portanto, eu não acho que essas mudanças tenham realmente qualquer tipo de grande impacto significativo sobre a atividade produtiva de pesquisadores. Os modos de produção mudaram: há 20 anos, não escrevemos mais coisas, nós as digitamos e esta é uma mudança que começou nos anos 1980 e continua à medida que os processos de trabalho e os computadores se tornam mais comuns.

Revista Linhas: No seu livro, intitulado “Livros na era digital”, você afirma na página 83 que “a publicação da pesquisa nunca é apenas uma maneira de divulgação de resultados. É uma parte intrínseca da economia da cultura de pesquisa, um complexo sistema de recompensas simbólicas e econômicas que molda a oportunidade de vida dos indivíduos para prosseguir a sua carreira no mundo da academia e da investigação científica e acadêmica”. A publicação torna-se uma obrigação para permanecer na academia?

John B. Thompson: O que tentava dizer é que a publicação é parte de uma ampla esfera econômica e simbólica em que os pesquisadores estão inseridos, e isto faz com que eles não estejam apenas sendo eficazes em disseminar os resultados de pesquisas, mas também estão construindo a sua carreira. Eles querem algo nos seus currículos, são como a RAE: importa o que e onde se publica. Portanto, publicar um artigo numa revista como a Nature faz uma grande diferença, porque é uma revista de alto impacto. O pesquisador põe isso no seu currículo e o seu artigo lhe dá uma enorme quantidade de crédito simbólico. E isso afeta a maneira como as pessoas veem aquele artigo e a forma como veem o seu autor. Assim, não é apenas sobre a obtenção dos resultados lá fora, como acabou de pôr no seu website, certo? Pode simplesmente colocá-lo no site, mas não obtém crédito simbólico com isso. Tem uma quantidade muito pequena de capital simbólico na economia cultural da pesquisa divulgar os resultados apenas dessa forma. Portanto, publicar em revistas de alto nível como a Nature ou parecida, traz-lhe algo mais, o que lhe permite, por sua vez, aumentar o seu capital econômico. Com quatro produções realmente qualificadas está em uma posição forte no 
mercado de transferência acadêmica. Pode mover-se entre universidades porque vão querer tê-lo por ser muito produtivo e, mais, produzir o tipo certo de coisas no tipo certo de revistas, o que o coloca numa posição forte para melhorar a sua própria carreira. Portanto, mais do que expor os resultados de pesquisas, é uma questão de melhorar o próprio currículo e construir carreira própria.

Ao escrever este livro eu queria que as pessoas percebessem que não se pode estudar as publicações acadêmicas como se fossem apenas para a divulgação dos resultados da pesquisa. As publicações acadêmicas são apenas uma pequena parte em um espaço de pesquisa mais complicado, em que pesquisadores e acadêmicos aspirantes tentam construir as suas carreiras. E a publicação é uma forma que permite fazer isso. E, assim, parece-me ser crucial poder ver-se isso. Simplesmente não se entende nada sobre publicação acadêmica se não se entender isto, percebe? As pessoas dizem, por exemplo, que é ultrajante submeter-se a esse processo pois essas revistas qualificadas são muito caras. Mas, então, por que os acadêmicos não esquecem isso, param de publicar neste espaço e simplesmente editem os seus próprios periódicos, chamando-o de Cambridge Journal of Sociology e apenas publicar ali?

Assim ninguém seria dono, não seria de propriedade de uma grande empresa - como a Elsevier - não custaria uma fortuna para as universidades poderem comprar e assim por diante. Por que não fazem isso, simplesmente? Ou criam a Biblioteca Pública de Ciências ou algo parecido? Na verdade, a razão por que vão publicar na Nature é para fazer parte de uma economia cultural da pesquisa. A Revista Nature tem alto padrão, então é um status muito alto! Assim, publicar um artigo nessa revista dá ao acadêmico autoridade e é importante para um acadêmico ter autoridade. Publicar no Cambridge Journal of Sociology, se ele existisse não lhe vai dar esse estatuto, autoridade. Assim, os acadêmicos não estão muito interessados em fazer isso porque a Pesquisa de Avaliação de Exercícios/RAE exige este padrão! Portanto todos nós temos de jogar esse jogo! E essa é a economia da cultura de pesquisa! Publicar é apenas parte disso.

Revista Linhas: Professor Thompson, agradecemos a sua disponibilidade.

John B. Thompson: Obrigado pela entrevista

Recebido em: maio de 2012 Aprovado em: setembro de 2012 